\title{
RISK FACTOR OF DRY EYES SYNDROME TOWARD ELDERLY WITH DIABETES MELLITUS
}

\author{
Trilaksana Nugroho'), Hari Peni Julianti'1), Arief Wildan'1), Arnila Novitasari \\ Saubig'), Andhika Guna Darma', Desti Putri Seyorini²) \\ 1)Lecturer at the Faculty of Medicine, Universitas Diponegoro \\ ${ }^{2)}$ Student of Medical Faculty, Universitas Diponegoro
}

\begin{abstract}
Background: Chronic metabolic disorder diabetes is a rapidly developing global problem with huge social, health and economic consequences. Indonesia is expected to reach 21.3 million people by 2030, and the incidence of diabetes is still increasing. Type 2 diabetes (T2DM) is an expanding global health problem closely related to the obesity epidemic. Type 2 diabetes (T2DM) is an expanding global health problem closely related to the obesity epidemic. Prolonged diabetes mellitus (DM) causes autonomic neuropathy in the lacrimal glands, which leads to reduced tear production, leading to dry eye syndrome (DES). This study aimed to analyze risk factor of dry eyes syndrome toward elderly with diabetes mellitus.

Subjects and Method: A cross sectional study was conducted at community health center Gunungpati and Graha Syifa clinic, Semarang. A sample of 28 elderlies was selected by consecutive sampling. The dependent variable was incidence of DES. The independent variables were gender, duration of DM, DM control, incidence of diabetic retinopathy, type of work, exposure to cigarette smoke, exposure to gadgets, incidence of hypertension, incidence of dyslipidemia, incidence of cataracts. The data were collected by examination, questionnaire and in-depth interview. The data were analyzed by logistic regression and Chi square.

Results: The logistic regression test results showed that gender, $(p=0.393)$, duration of diabetes $(p=0.208)$, and the incidence of diabetic retinopathy $(p=0.264)$ were not risk factors for DES. The results of the logistic regression test showed that controlling diabetes $(p=0.002)$, gadget exposure $(\mathrm{p}=0.023)$ were risk factors for DES incidence. DM control and gadget exposure contributed $75 \%$ as risk factors for DES events.
\end{abstract}

Conclusion: Uncontrolled DM and exposure to gadgets $>2$ hours continuously a day are risk factors for DES.

Keywords: Dry eyes, Diabetes Mellitus, Elderly

\section{Correspondence:}

Trilaksana Nugroho. Faculty of Medicine, Universitas Diponegoro. Jl. Prof. Sudarto No.13, Tembalang, Kec. Tembalang, Kota Semarang, Jawa Tengah 50275.

The $7^{\text {th }}$ International Conference on Public Health Solo, Indonesia, November 18-19, 2020| 394 https://doi.org/10.26911/the7thicph.05.26 